\title{
The Importance of Lymphovascular Invasion at Radical Cystectomy
}

\author{
Sacit Nuri Gorgel*, Osman Kose, Ozan Horsanal, Evren Sahin, Ugur Balci, Kutan Ozer, \\ Cengiz Girgin
}

Izmir Katip Celebi University, Ataturk Training and Reseacrh Hospital, Department of Urology, Izmir, Turkey

Email address:

sngorgel@hotmail.com (S. N. Gorgel)

\section{To cite this article:}

Sacit Nuri Gorgel, Osman Kose, Ozan Horsanal1, Evren Sahin, Ugur Balci, Kutan Ozer, Cengiz Girgin. The Importance of Lymphovascular Invasion at Radical Cystectomy. Clinical Medicine Research. Vol. 4, No. 2, 2015, pp. 34-37. doi: 10.11648/j.cmr.20150402.12

\begin{abstract}
Objectives: To investigate relationship between the lymphovascular invasion(LVI) and tumor characteristics and to evaluate effect on survival of LVI in patients who underwent radical cystectomy because of bladder cancer. Materials and Methods: Five hundred and six patients were enrolled the study between 1990 and 2013. Patients were divided into two groups in terms of lymphovascular invasion at final pathology after radical cystectomy. There were 108 patients with LVI(group1) and 244 patients without LVI(group2). Both groups were compared in terms of clinicopathologic features and survival. Results: There was no statically different for gender in both group $(\mathrm{p}=0,222)$.Lymh node involvement, grade, and $\mathrm{p} T$ stage were higher significantly in group $1(\mathrm{p}<0,05)$. Positive lymph node number was $2.3 \pm 3.1$ in group 1 and $0.6 \pm 2.1$ in group $2(\mathrm{p}<0.001)$. Lymph node density was $24.3 \pm 30.1$ in group 1 and $5.6 \pm 9.2$ in group $2(p<0.001)$.Estimated mean survival time was $27.2 \pm 3.4$ months in group 1 and $80.2 \pm 8.1$ months in group $2(\mathrm{p}<0.001)$. Conclusions: Lymphovascular invasion is an independent prognostic factor for disease specific survival and effects survival negatively in patients who underwent radical cystectomy for bladder cancer. Patients with lymphovascular invasion should be considered for close monitoring after cystectomy.
\end{abstract}

Keywords: Lymphovascular Invasion (LVI), Radical Cystectomy, Survival, Urethelial Carcinoma

\section{Introduction}

Bladder cancer is the ninth most common cancer diagnosis worldwide, with more than 330,000 new cases each year and more than 130,000 deaths per year, with an estimated malefemale ratio of 3.8:1.0. At any point in time, 2.7 million people have a history of urinary bladder cancer [1].

At the initial diagnosis of bladder cancer, $70 \%$ of cases are diagnosed as non-muscle-invasive bladder cancer and approximately $30 \%$ as muscle invasive bladder cancer [2]. Approximately one-third of patients diagnosed with muscle invasive bladder cancer have undetected metastases at the time of treatment for the primary tumour [3], while $25 \%$ of patients who undergo radical cystectomy present with lymph node involvement at the time of surgery. Radical cystectomy with extended bilateral lymphadenectomy is the standard therapy in patients with muscle invasive disease or in some cases of high grade superficial cancer refractory to conservative treatment [4].

Traditionally, independent variables of disease specific survival are grading, pathological stage and presence of lymph node involvement [5-7]. The prognostic value of lymphovascular invasion (LVI) has previously been investigated by others [8,9].

The aim of our study was to assess prognostic role of lymphovascular invasion at final pathology after radical cystectomy for bladder cancer.

\section{Materials and Methods}

Five hundred and six consecutive patients underwent radical cystectomy with bilateral pelvic lymphadenectomy and consequently a urinary diversion for a primary muscleinvasive and reftactory superficial bladder tumor from June 1990 to July 2013. Datas of 352 patients of all were achieved and analyzed retrospectively. Patients were divided into two groups in terms of lymphovascular invasion at final pathology after radical cystectomy for bladder cancer.

There were 108 patients with lymphovascular invasion (group 1) and 244 patients without lymphovascular invasion 
at cystectomy specimen (group 2). Both groups were compared in terms of clinicopathologic features and survival.

LVI is defined as the presence of neoplastic cells within an endothelium-lined space. Patients with a non-transitional cell carcinoma or submitted to a salvage procedure or neoadjuvant/adjuvant chemo-radiotherapy were excluded

Chi-squared tests were used to evaluate the association between categorical variables. Independent $T$ tests were used to compare parametric values. The Kaplan-Meier method was used to calculate survival functions, $p$-value of less than 0.05 was considered statistically significant. The SPSS (Statistical Package for Social Science, Chicago, IL, USA) software was used for the statistical analysis.

\section{Results}

Of the 352 patients, 326 were males and 26 females. LVI was present in 108 pathological specimens $(30 \%)$. The mean age was $60.80 \pm 8.6$ years in group 1 and $61.20 \pm 9.2$ years in group $2(\mathrm{p}=0,803)$. There was no statically different for gender in both groups $(\mathrm{p}=0,222)$. Lymh node involvement, grade, and $\mathrm{p} \mathrm{T}$ stage were higher significantly in group $1(\mathrm{p}<0,001, \mathrm{p}<0,001, \mathrm{p}<0,001$ respectively $)$. Demographic and histopathological features stratified according to LVI are listed in Table 1.

Table 1. Demographic and histopathological features of patients.

\begin{tabular}{llll}
\hline & LVI $\pm($ n) & LVI- (n) & P value \\
\hline Mean age & $60.84 \pm 8.6$ & $61.2 \pm 9.2$ & $0.803^{\mathrm{a}}$ \\
Male & 96 & 230 & $0.222^{\mathrm{b}}$ \\
Female & 12 & 14 & \\
Grade 1 & 2 & 14 & $<0.001^{\mathrm{b}}$ \\
Grade 2 & 10 & 60 & \\
Grade 3 & 96 & 170 & \\
pT1 & 2 & 64 & $<0.001^{\mathrm{b}}$ \\
pT2 & 16 & 10 & \\
pT3 & 46 & 44 & $<0.001^{\mathrm{b}}$ \\
pT4 & 4 & 18 & \\
Lymh node involvement & 78 & 38 & \\
\hline
\end{tabular}

${ }^{\mathrm{a}}$ independent student $\mathrm{t}$ test, ${ }^{\mathrm{b}}$ chi square test

Mean follow up time was $15.10 \pm 12.7$ months in group 1 and $34.7 \pm 34.7$ in group $2(\mathrm{p}<0,001)$. Positive lymph node number was $2.3 \pm 3.1$ in group 1 and $0.6 \pm 2.1$ in group 2 $(\mathrm{p}<0.001)$. Lymph node density was $24.3 \pm 30.1$ in group 1 and 5.6 \pm 9.2 in group $2(\mathrm{p}<0.001)$ (Table2). Estimated mean survival time was $27.2 \pm 3.4$ months in group 1 and $80.2 \pm 8.1$ months in group $2(\mathrm{p}<0.001)$ (Figure 1).

\section{Survival Functions}

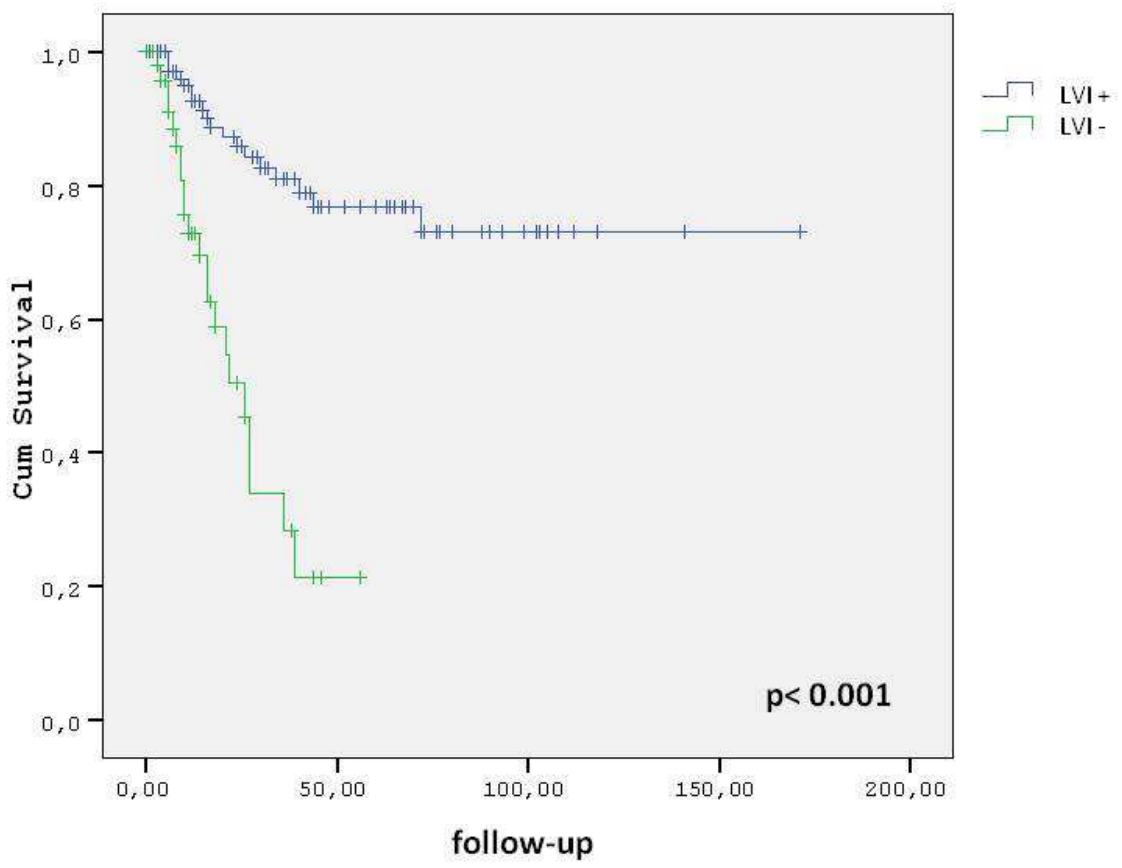

Figure 1. The effect on the survival of lymphovascular invasion (Kaplan-Meier)

In cox regression analyses; lymphovascular invasion $(\mathrm{p}<0.005), \mathrm{p}$ T stage $(\mathrm{p}<0,001)$ and lymph node involvement $(p=0,02)$ were independent significant prognostic for diseasespecific survival.
Table 2. Association of lymphovascular invasion with lymp node status and follow-up time.

\begin{tabular}{llll}
\hline & LVI+ & LVI- & p* \\
\hline Mean follow-up time (months) & $15.1 \pm-12.27$ & $34.7 \pm 34.7$ & $<0.001$ \\
Positive lymp node number & $2.3 \pm 3.1$ & $0.6 \pm 2.1$ & $<0.001$ \\
Lymph node density & $24.3 \pm 30.1$ & $5.6 \pm 19.2$ & $<0.001$ \\
Estimated mean survival time & $27.2 \pm 3.4$ & $80.2 \pm 8.1$ & $<0.001$ \\
\hline
\end{tabular}

*Indipendent student $\mathrm{t}$ test 


\section{Discussion}

LVI is the first step of metastatic spread in the natural history of cancer and corresponds to infiltration of the local vascular and lymphatic microcirculation by tumor cells. LVI can be detected on heamatoxylin and eosin stained sections [10].

The predictive value and prevalence of lymphovascular invasion is strongly dependent on the type of cancer. In other words, LVI in one type of cancer may be much less important than LVI in another type of cancer.

Generally speaking, it is associated with lymph node metastases which themselves are predictive of a poorer prognosis [11-13]. In the context of (histologically) proven lymph node metastases, LVI may have less prognostic significance or no prognostic significance. In other studies, however, LVI was not a predictor of lymph node metastases [14] or survival [5,15]. In our study, lymph node involvement was significant higher in patients with LVI.

Stein et al. demonstrated that LVI was a significant and independent prognostic factor for cancer-specific survival, as well as pathological staging and presence of node metastasis. In the present study, we found similar results between the lymphovascular invasion and survival and prognostic factors [4]. Herrmann et al. reported that pathological tumour stage $(p<0.0001)$, lymph node status $(p=0.004)$ and LVI $(p=0.001)$ were independent prognostic factors associated with unfavourable overall survival in a cohort of 833 patients [16]. Canter et al. analysed data from 356 patients treated with radical cystectomy at the University of Pennsylvania and at univariate analysis found that the presence of LVI conferred a risk for decreased overall, cancer-specific and recurrence-free survival $(\mathrm{p}<0.0001)$ [9]. Bassi et al. found that only tumor stage and nodal involvement were independent prognostic variables on multivariate analysis [5]. Lymphovascular invasion is also important for superficial bladder cancer especially high grade tumors $[17,18]$.

In our multivariate analyse; lymphovascular invasion, pT stage and lymph node involvement were independent significant prognostic for disease-specific survival

Other parameters were association of lymphovascular invasion with positive lymph node number and lymph node density in our study. Positive lymph node number and lymph node density are significant prognostic factors for disease spesific survival [19-21]. In our study, mean positive lymph node number and lymph node density were significantly higher for lymphovascular invasion. In the presence of lymphovascular invasion, lymph nodes should be examined carefully and considered for close monitoring after cystectomy

There are several limitations in this study including retrospective design, single-centre and small size of groups. Our results should be supported by prospective randomized studies.

\section{Conclusion}

Lymphovascular invasion is an independent prognostic factor for disease specific survival and effects survival negatively in patients who underwent radical cystectomy for bladder cancer. Patients with lymphovascular invasion should be considered for close monitoring after cystectomy.

\section{References}

[1] Ploeg M, Aben KK, Kiemeney LA. The present and future burden of urinary bladder cancer in the world. World J Urol, 27(3):289-93, 2009.

[2] Vaidya A, Soloway MS, Hawke C, et al. De novo muscle invasive bladder cancer: is there a change in trend? J Urol, 165(1):47-50, 2001.

[3] Prout GR Jr, Griffin PP, Shipley WU. Bladder carcinoma as a systemic disease. Cancer, 43(6):2532-9, 1979.

[4] Stein JP, Lieskovsky G, Cote R, Groshen S, Feng AC, Boyd S, Skinner E, Bochner B, Thangathurai D, Mikhail M, Raghavan $\mathrm{D}$ and Skinner DG. Radical cystectomy in the treatment of invasive bladder cancer: long-term results in 1,054 patients. $\mathrm{J}$ Clin Oncol, 19(3):666-675, 2001.

[5] Bassi P, Ferrante GD, Piazza N, Spinadin R, Carando R, Pappagallo $G$ and Pagano F. Prognostic factors of outcome after radical cystectomy for bladder cancer: a retrospective study of a homogeneous patient cohort. J Urol, 161(5): 1494-7, 1999.

[6] Herrmann E, Stöter E, Van Ophoven A, Bierer S, Bolenz C, Hertle L and Christian Wülfing. The prognostic impact of pelvic lymph node metastasis and lymphovascular invasion on bladder cancer. Int J Urol, 15:607-611, 2008.

[7] Karakiewicz PI, Shariat SF, Palapattu GS, Gilad AE, Lotan Y, Rogers CG, Vazina A, Gupta A, Bastian PJ, Perrotte P, Sagalowsky AI, Schoenberg M and Lerner SP. Nomogram for predicting disease recurrence after radical cystectomy for transitional cell carcinoma of the bladder. J Urol, 176: 13541362,2006

[8] Kunju LP, You L, Zhang Y, Daignault S, Montie JE and Lee CT. Lymphovascular invasion of urothelial cancer in matched transurethral bladder tumor resection and radical cystectomy specimens. J Urol, 180:1928-1932, 2008.

[9] Canter D, Guzzo T, Resnick M, Magerfleisch L, Sonnad S, Bergey M, Tomazewski J, Vaughn D, Van Arsdalen K and Malkowicz B. The presence of lymphovascular invasion in radical cystectomy specimens from patients with urothelial carcinoma portends a poor clinical prognosis. BJU Int,102(8): 952-927,2008.

[10] Lopez JI, Angulo JC. The prognostic significance of vascular invasion in stage T1 bladder cancer. Histopathology, 27:27-33, 2008.

[11] Schoppmann, SF.; Bayer, G.; Aumayr, K.; Taucher, S.; Geleff, S.; Rudas, M.; Kubista, E.; Hausmaninger, H. et al. "Prognostic value of lymphangiogenesis and lymphovascular invasion in invasive breast cancer.". Ann Surg, 240 (2): 30612,2004 .

[12] Fang, WL.; Chang, SC.; Lin, JK.; Wang, HS.; Yang, SH.; Jiang, JK.; Chen, WC.; Lin, TC "Metastatic potential in T1 and T2 colorectal cancer." Hepatogastroenterology, 52 (66): 1688-91, 2005. 
[13] Moreira, LF.; Kenmotsu, M.; Gochi, A.; Tanaka, N.; Orita, K "Lymphovascular and neural invasion in low-lying rectal carcinoma.". Cancer Detect Prev, 23 (2): 123-8, 1999.

[14] Jaeger TM, Weidner N, Chew K, et al. Tumor angiogenesis correlates with lymph node metastases in invasive bladder cancer. J Urol, 154:69-71, 1999.

[15] Hara S, Miyake H, Fujisawa M, et al. Prognostic variables in patients who have undergone radical cystectomy for transitional cell carcinoma of the bladder. Jpn J Clin Oncol, 31:399-402, 2001.

[16] Herrmann E, Stöter E, Van Ophoven A, Bierer S, Bolenz C, Hertle L and Christian Wülfing. The prognostic impact of pelvic lymph node metastasis and lymphovascular invasion on bladder cancer. Int J Urol, 15: 607-611, 2008.

[17] Branchereau J, Larue S, Vayleux B, Karam G, Bouchot O, Rigaud J. Prognostic value of the lymphovascular invasion in high-grade stage pT1 bladder cancer. Clin Genitourin Cancer, Jun; 11(2):182-8, 2013.
[18] Tilki D, Shariat SF, Lotan Y, Rink M, Karakiewicz PI, Schoenberg MP, Lerner SP, Sonpavde G, Sagalowsky AI, Gupta A. Lymphovascular invasion is independently associated with bladder cancer recurrence and survival in patients with final stage T1 disease and negative lymph nodes after radical cystectomy. BJU Int, Jun;111(8):1215-21,2013.

[19] Leissner J, Hohenfellner R, Thuroff JW, Wolf HK. Lymphadenectomy in patients with transitional cell carcinoma of the urinary bladder; significance for staging and prognosis. BJU Int, 85:817-823, 2003.

[20] Stein JP, Cai J, Groshen S, Skinner DG. Risk factors for patients with pelvic lymph node metastases following radical cystectomy with en bloc pelvic lymphadenectomy: concept of lymph node density. J Urol, 170:35-41, 2003.

[21] Herr HW. Superiority of ratio based lymph node staging for bladder cancer. J Urol, 169: 943-5, 2003. 